IOS Press

\title{
Erratum
}

\section{Erratum to: Fluid-structure coupling analysis of multi-DOF motor considering hydrodynamic bearing's cavitation effect}

Li Zheng $^{\mathrm{a}, *}$, Chen Qing ${ }^{\mathrm{a}}$, Xiao Yu ${ }^{\mathrm{a}}$, Wang Dixin ${ }^{\mathrm{a}}$, Wang Leiyong ${ }^{\mathrm{a}}$ and Wang Qunjing ${ }^{\mathrm{b}}$ ${ }^{a}$ School of Electrical Engineering, Hebei University of Science and Technology, Shijiazhuang, China ${ }^{\mathrm{b}}$ National Engineering Laboratory of Energy-saving Motor \& Control Technique, Anhui University, Hefei, China

[International Journal of Applied Electromagnetics and Mechanics, 58(4) 2018, 451-469, DOI 10.3233/JAE-180064]

https://content.iospress.com/articles/international-journal-of-applied-electromagnetics-andmechanics/jae180064

On page 465, Fig. 15 the description is in Chinese, however this should be in English. The correct figure is as follows:

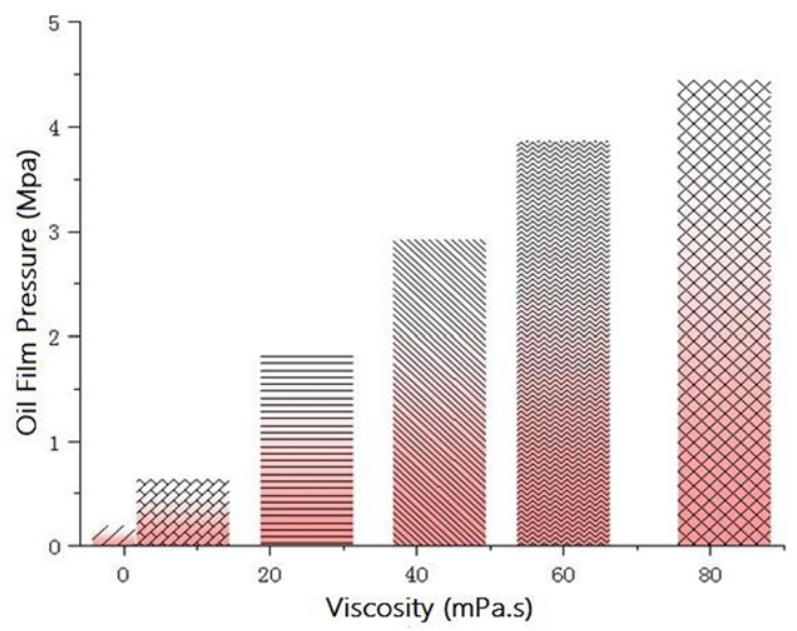

Fig. 15. Oil film pressure distribution at different viscosities.

\footnotetext{
*Corresponding author: Li Zheng, School of Electrical Engineering, Hebei University of Science and Technology, Shijiazhuang 050018, China. E-mail: Lizheng@hebust.edu.cn.
} 